OPEN ACCESS

Edited by:

Antonella Gasbarri, University of L'Aquila, Italy

Reviewed by: Sean Commins,

Maynooth University, Ireland Dubravko Radovan Bokonjic, Military Medical Academy, Serbia

*Correspondence: Miroljub Popović miroljub@um.es

Received: 19 November 2018 Accepted: 23 November 2018

Published: 06 December 2018

Citation:

Morales-Delgado N, Popović N, De la Cruz-Sánchez E, Caballero Bleda M and Popović M (2018) Time-of-Day and Age Impact on Memory in Elevated Plus-Maze

Test in Rats.

Front. Behav. Neurosci. 12:304. doi: 10.3389/fnbeh.2018.00304

\section{Time-of-Day and Age Impact on Memory in Elevated Plus-Maze Test in Rats}

\author{
Nicanor Morales-Delgado ${ }^{1,2}$, Natalija Popović ${ }^{1,2}$, Ernesto De la Cruz-Sánchez ${ }^{3}$, \\ María Caballero Bleda ${ }^{1,2}$ and Miroljub Popović ${ }^{1,2 *}$
}

${ }^{1}$ Department of Human Anatomy and Psychobiology, Faculty of Medicine, University of Murcia, Murcia, Spain, ${ }^{2}$ Institute of Biomedical Research of Murcia (IMIB), Virgen de la Arrixaca University Hospital, University of Murcia, Murcia, Spain, ${ }^{3}$ Department of Physical Activity and Sport, Faculty of Sport Science, University of Murcia, Murcia, Spain

The purpose of the present study was to establish the effect of daytime and aging on memory in rats in the Elevated Plus-Maze (EPM) test. Young (2-months) and aged (18-months) male Wistar rats were exposed to the EPM test, at the beginning, mid-time or at the end of the light period. On the acquisition trial, the animals were placed individually at the end of one of the open arms of the EPM and the latency to enter in the enclosed arms was registered (cut-off time $60 \mathrm{~s}$ ). The test was repeated $24 \mathrm{~h}$ later on. A longer latency period to reach the enclosed arm indicated poor retention compared to significantly shorter latencies. There were no significant differences between groups on the acquisition trial. In all tested periods, the latency time on the $24 \mathrm{~h}$ retention trial was significantly shorter in the young rats compared to the old ones. Furthermore, in the early and mid-time period of the light period, the young rats showed significantly decreased transfer latency $(T L)$ time on the $24 \mathrm{~h}$ retention trial in comparison with the acquisition trial. In the aged rats, the TL time on the $24 \mathrm{~h}$ retention trial was significantly longer at the end of the light period, in comparison to the two other testing periods. In conclusion, aging significantly affects memory and the more critical period for memory process in both young and old animals, particularly at the end of the light period of the circadian cycle.

Keywords: aging, circadian rhythm, elevated plus-maze, memory, rat

\section{INTRODUCTION}

The extant literature indicates that spatial navigation and spatial memory, ones of the crucial abilities for everyday living and survive, decline with aging, in rodents, non-human primates and humans (Foster et al., 2012; Klencklen et al., 2012; Colombo et al., 2017; Lester et al., 2017). Although the impact of time-of-day on cognitive function has been matter of interest for many years (Gerstner and Yin, 2010), there are scarce data on the relationship between spatial memory, aging and time-of-day in rodents. Several studies indicate that young rodents performs better during the active phase than during the rest period, in different spatial memory tasks, such as Morris water maze (Gritton et al., 2012; Martin-Fairey and Nuñez, 2014), 8-arm radial maze (Hauber and Bareiß, 2001), six point alley-T-maze (Hoffmann and Balschun, 1992), context-dependent fear conditioning (Valentinuzzi et al., 2001) and novel location recognition tasks (Takahashi et al., 2013). However, the time-of-day impact has not been demonstrated when rats were tested at the beginning 
and at the end of the light period, in the context-dependent fear conditioning task and Morris water maze (McDonald et al., 2002). In contrast, Winocur and Hasher (2004) found that young rats tested within $1 \mathrm{~h}$ after the beginning of the dark period, performed worsen a non-matching-to-sample variant of the water maze, than a group tested within $1 \mathrm{~h}$ before the end of dark period. However, the reverse situation was demonstrated in old rats.

The Elevated Plus-Maze (EPM) has been initially used as a test of anxiety in rats (Pellow et al., 1985) and mice (Lister, 1987) and shortly after as a test to evaluate memory in mice and rats (Itoh et al., 1990; Sharma and Kulkarni, 1992). Using this test, an age-related memory decline was found in rats (Haider et al., 2014; Nade et al., 2015) and mice (Reddy and Kulkarni, 1998; Carrié et al., 1999; Raghavendra and Kulkarni, 2001; Parle and Dhingra, 2003; Patil et al., 2003; Singh et al., 2003; Joshi and Parle, 2006a,b; Bansal and Parle, 2011). In both species, the animals were tested during the rest (light) phase of the circadian rhythm without tendency to evaluate time-of-day effect. The purpose of the present study was to evaluate the effects of aging and daytime of the light period, on memory in the EPM test.

\section{MATERIALS AND METHODS}

\section{Animals}

The animal maintenance (three rats per cage; $22 \pm 1^{\circ} \mathrm{C}$ room temperature; $30 \%$ humidity; food and water available ad libitum, lights on from 09:00 $\mathrm{h}$ to 21:00 h) and experimentation on 36 young (2-months, body weight: $242.3 \pm 11.0 \mathrm{~g})$ and 48 old (18-months, body weight: $864.9 \pm 128.1 \mathrm{~g}$ ) male Wistar rats were proceeded in accordance with the European Communities Council Directive of November 24, 1986 (86/609/EEC) and the guidelines issued by the Spanish Ministry of Agriculture, Fishing and Feeding (Royal Decree 1201/2005 of October 21, 2005) and were approved by the Institutional Animal Ethics Committee. All rats were individually handled for 2 days $\times 2 \mathrm{~min}$, before the beginning of the training day. The EPM test was performed during the light period: in the morning (10:00-11:30 h; defined as Zeitgeber time (ZT) ZT1-2.5), early afternoon (14:00-15:30 h, defined as ZT5-6.5) and late afternoon (19:00-20:30 h, defined as ZT10-11.5). All efforts were made to minimize the number of animals used and their suffering.

\section{Elevated Plus-Maze (EPM)}

EPM apparatus was made of black plywood and consisted of both two opposed open and enclosed arms $(50 \mathrm{~cm}$ length $\times 10 \mathrm{~cm}$ width $\times 40 \mathrm{~cm}$ high for closed arms), and an open central square $(10 \mathrm{~cm}$ length $\times 10 \mathrm{~cm}$ width). The maze was elevated $80 \mathrm{~cm}$ above the floor. On the acquisition trial, the rats were placed individually at the end of the open arm, facing it away from the central platform. The time that the animal took to move from the open arm to either one of the enclosed arms was registered by two experimenters. The entry into the enclosed arm was recorded when an animal's all four paws passed the line dividing the central square from the open arms. The same procedure was repeated on the
$24 \mathrm{~h}$ retention trial. Each animal that on the acquisition trial failed to enter the enclosed arm within $60 \mathrm{~s}$ or that fell off the maze (either during acquisition or retention trial) was excluded from the experiment. The criterium was achieved by 32 young animals $(10,10$ and 12 at the ZT1-2.5, ZT5-6.5 and ZT10-11.5, respectively) and by 24 old rats $(7,9$ and 8 at the ZT1-2.5, ZT5-6.5 and ZT10-11.5, respectively). To become acquainted with the EPM, the rats were allowed to explore the apparatus for $20 \mathrm{~s}$ after reaching the enclosed arm and then returned to its home cage. A longer transfer latency (TL) period to reach the enclosed arm on the second trial indicated poor retention compared to significantly shorter latencies. The apparatus was wiped clean with $70 \%$ ethanol before testing each animal.

\section{Statistical Analysis}

Descriptive data are presented as mean, median and percentiles (P10, P25, P75 and P90). The statistical analysis was performed using SPSS 24.0 software (IBM Corp., Armonk, NY, USA). A General Linear Model repeated measures analysis was run to evaluate the effects of trails, age and time-of-day on TL, examining also two-way and simple main effects. In order to normalized data distribution natural logarithmic transformation was applied before the statistical analysis. Statistical significance was accepted at a Bonferroni-adjusted alpha level of 0.025 or 0.05 , depending on the number of the comparisons made. TL comparison between the acquisition and the $24 \mathrm{~h}$ retention trials, in each time of the day, for each group (young and old animals), was done using a paired sample $t$-test.

\section{RESULTS}

The General Linear Model repeated measures analysis showed significant within-subjects effect of trial on TL $\left(F_{(1,50)}=17.603\right.$, $p=0.0001)$ and trial and age $\left(F_{(2,50)}=7.358, p=0.009\right)$, but not an interaction of trial, age and time of the day $\left(F_{(2,50)}=0.151\right.$, $p=0.861)$ and trial and time-of-day $\left(F_{(2,50)}=1.372, p=0.263\right)$. The same analysis showed significant between-subjects effect on TL and age $\left(F_{(1,50)}=45.697, p=0.0001\right)$, TL and time-of-day $\left(F_{(2,50)}=4.471, p=0.016\right)$ but not on TL, age and time-of-day $\left(F_{(2,50)}=0.860, p=0.429\right)$.

At the acquisition trial there was not statistically significant simple main effect of the time-of-day on TL in both young and old rats $\left(F_{(2,50)}=0.005, p=0.995, F_{(2,50)}=0.452, p=0.639\right.$, respectively) and effect of age in each time of the day on TL as follows: ZT1-2.5 $\left(F_{(1,50)}=0.903, p=0.347\right)$; ZT5-6.5 $\left(F_{(1,50)}=1.067, p=0.306\right)$ and ZT10-11.5 $\left(F_{(1,50)}=3.855\right.$, $p=0.055)$. However, at the $24 \mathrm{~h}$ retention trial there was a statistically significant simple main effect of the time-of-day on $T L$ in old rats $\left(F_{(2,50)}=3.355, p=0.043\right)$, but not in the young ones $\left(F_{(2,50)}=3.116, p=0.053\right)$. In the old animals, the TL at the end of rest period was significantly higher in comparison to the ZT1-2.5 $(p=0.0001)$ and ZT5-6.5 session $(p=0.0001$; Figure 1). The statistically significant simple main effect of age in each time of the day on TL was found as follows: ZT1-2.5 $\left(F_{(1,50)}=8.572, p=0.005\right)$, ZT5-6.5 $\left(F_{(1,50)}=19.827, p=0.0001\right)$ and ZT10-11.5 $\left(F_{(1,50)}=23.201\right.$, 


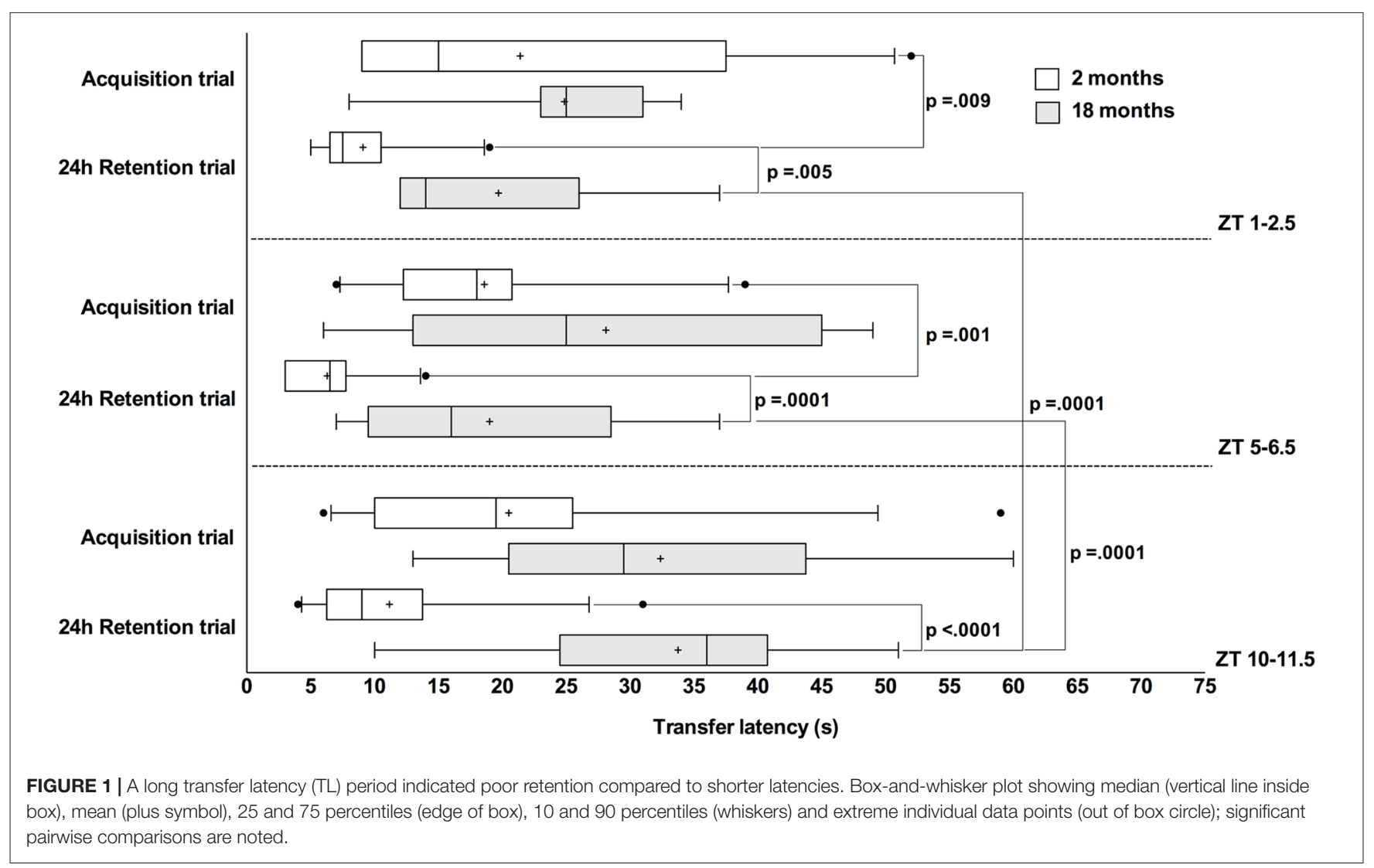

$p=0.0001$ ) indicating that $\mathrm{TL}$ at the $24 \mathrm{~h}$ retention trial was significantly higher in old rats vs. young ones in all tested periods (Figure 1).

The paired sample $t$-test reveals statistical differences between acquisition and $24 \mathrm{~h}$ retention trials for young rats tested at the ZT1-2.5 $\left(t_{(9)}=3.342, p=0.009\right)$ and at the ZT5-6.5 period $\left(t_{(9)}=4.833, p=0.001\right)$, but not at the ZT10-11.5 period $\left(t_{(11)}=1.923, p=0.081\right)$. There were no statistical differences between trials in old rats tested in the ZT1-2.5 $\left(t_{(6)}=1.100\right.$, $p=0.314)$, ZT5-6.5 $\left(t_{(8)}=0.879, p=0.405\right)$ and ZT10-11.5 $\left(t_{(7)}=0.177, p=0.864\right)$.

\section{DISCUSSION}

The results from the present study reveal that during the acquisition trial there are no significant differences in TL between aged and young rats. Moreover, neither in young or aged animals there were differences between three tested periods (ZT1-2.5; ZT5-6.5 and ZT10-11.5), suggesting altogether that there were no significant effects of the age and the timeof-day on motor or visual abilities nor motivation to escape from the open arm in the EPM. Similarly, Raghavendra and Kulkarni (2001); Jain et al. (2002) and Patil et al. (2003) did not found significant differences in the performance of the acquisition trial between 14 months and 16 months and 3 months aged mice. However, some other studies, demonstrated significantly higher TL on acquisition trial of 14-16 months aged mice (Reddy and Kulkarni, 1998; Singh et al., 2003) and 10-12 months aged Sprague-Dawley rats (Sharma and Kulkarni, 1992) than in the corresponding 2-3 months young animals.

Independently of the time of the day when the EPM test was performed: between 08:00 $\mathrm{h}$ and 15:00 h (Singh et al., 2003; Bansal and Parle, 2011), 10:00 and 13:00 h (Raghavendra and Kulkarni, 2001) or 09:00-18:00 h (Reddy and Kulkarni, 1998; Carrié et al., 1999; Jain et al., 2002), the TL from the open to the enclosed arm on $24 \mathrm{~h}$ retention trial was higher in 14-18 months aged mice than in the $2-3$ mice young ones. Moreover, the TL between trials significantly decreased in young but not in the old animals (Raghavendra and Kulkarni, 2001; Jain et al., 2002; Singh et al., 2003). The longitudinal studies performed in young ( 3 months) and aged (16 months) Swiss mice showed faster forgetting in aged than in young animals (Patil et al., 2003).

In the EPM test performed in the light period, aged Wistar rats (22-24 months) exhibited significantly longer TL on the $24 \mathrm{~h}$ retention trial compared to the young rats (4-5 months; Haider et al., 2014). In the present study, independently of the ZT period, the TL on the $24 \mathrm{~h}$ retention trial was significantly shorter in the young Wistar rats, compared to the old ones suggesting deficit in spatial memory in the aged animals. Curiously, in opposite to our and all previously mentioned findings, Sharma and Kulkarni (1992) found that during the light period (09:00-12:00 h) the TL significantly decrease on the $24 \mathrm{~h}$ retention trial in 10-12 months but not in the 2-3 months aged Sprague-Dawley rats. 
In contrast to the data of McDonald et al. (2002) that showed no differences between rats (strain and age not specified) tested at the beginning (ZT2) and at the end of the light period (ZT11) in the Morris water maze task, the present study indicates that in both groups, young and aged Wistar rats, the end of the light period maybe considered as the more vulnerable period for memory formation in the EPM test. Namely, in young rats, only during the beginning and mid-time period of the light period occurred significant decrease in the TL between trials, while in the aged rats, the TL time on the $24 \mathrm{~h}$ retention trial was significantly longer at the end of the light period in comparison to the two other testing periods. Similarly, in humans, the worsen period to perform cognitive tasks is at the end of the resting period (early morning hours: from 3 am until 7 am; Evans et al., 2017). Since sleeping helps the consolidation of spatial memory (Vorster and Born, 2015), the possibilities of memory consolidation disruption could be higher at the end of the resting period than at the beginning and mid-time of the same period.

\section{CONCLUSION}

Aging significantly affects memory in the EPM test and it seems that during the light phase of the circadian cycle, its ending period maybe the more critical period for memory process in both young and old rats.

\section{REFERENCES}

Bansal, N., and Parle, M. (2011). Beneficial effect of chyawanprash on cognitive function in aged mice. Pharm. Biol. 49, 2-8. doi: 10.3109/13880209.2010. 489904

Carrié, I., Debray, M., Bourre, J.-M., and Francès, H. (1999). Ageinduced cognitive alterations in OF1 mice. Physiol. Behav. 66, 651-656. doi: 10.1016/s0031-9384(99)00003-7

Colombo, D., Serino, S., Tuena, C., Pedroli, E., Dakanalis, A., Cipresso, P., et al. (2017). Egocentric and allocentric spatial reference frames in aging: a systemic review. Neurosci. Biobehav. Rev. 80, 605-621. doi: 10.1016/j.neubiorev.2017. 07.012

Evans, M. D. R., Kelley, P., and Kelley, J. (2017). Identifying the best times for cognitive functioning using new methods: matching University times to undergraduate chronotypes. Front. Hum. Neurosci. 11:188. doi: $10.3389 /$ fnhum.2017.00188

Foster, T. C., DeFazio, R. A., and Bizon, J. L. (2012). Characterizing cognitive aging of spatial and contextual memory in animal models. Front. Aging Neurosci. 4:6. doi: $10.3389 /$ fnagi.2012.00012

Gerstner, J. R., and Yin, J. C. (2010). Circadian rhythms and memory formation. Nat. Rev. Neurosci. 11, 577-588. doi: 10.1038/nrn2881

Gritton, H. J., Kantorowski, A., Sarter, M., and Lee, T. M. (2012). Bidirectional interaction between circadian entrainment and cognitive performance. Learn. Mem. 19, 126-141. doi: 10.1101/lm.023499.111

Haider, S., Saleem, S., Perveen, T., Tabassum, S., Batool, Z., Sadir, S., et al. (2014). Age-related learning and memory deficits in rats: role of altered brain neurotransmitters, acetylcholinesterase activity and changes in antioxidant defense system. Age 36, 1291-1302. doi: 10.1007/s11357-014-9653-0

Hauber, W., and Bareiß, A. (2001). Facilitative effects of an adenosine $A_{1} / A_{2}$ receptor blockade on spatial memory performance of rats: selective enhancement of reference memory retention during the light period. Behav. Brain Res. 118, 43-52. doi: 10.1016/s0166-4328(00)00307-7

Hoffmann, H. J., and Balschun, D. (1992). Circadian differences in maze performance of $\mathrm{C} 57 \mathrm{Bl} / 6$ Ola mice. Behav. Processes 27, 77-84. doi: 10.1016/0376-6357(92)90017-8

Itoh, J., Nabeshima, T., and Kameyama, T. (1990). Utility of an elevated plus-maze for the evaluation of memory in mice: effects of nootropics,

\section{DATA AVAILABILITY}

The datasets generated for this study are available on request to the corresponding author.

\section{AUTHOR CONTRIBUTIONS}

NM-D, NP, EC-S, MCB and MP contributed to the design of the study, wrote the protocol, managed the literature searches, contributed to drafting the work and have approved the final manuscript. NM-D, NP and MP performed the experiments. EC-S and MP undertook the statistical analysis.

\section{FUNDING}

Funding for this study was provided by the Health Council of Murcia Region, Spain (MCB), the Spanish Ministry of Economy and Competitiveness (BFU2014-57516-P; LPL, JLF), the European Regional Development Fund (EFDR; LPL) and Seneca Foundation 19904/GERM/15 (LPL, SMP). The funding sources had no further role in the study design; in the collection, analysis and interpretation of the data; in the writing of the report; or in the decision to submit the article for publication.

scopolamine and electroconvulsive shock. Psychopharmacology 101, 27-33. doi: $10.1007 / \mathrm{bf} 02253713$

Jain, N. K., Patil, C. S., Kulkarni, S. K., and Singh, A. (2002). Modulatory role of cyclooxygenease inhibitors in aging- and scopolamine or lipopolysaccharideinduced cognitive dysfunction in mice. Prog. Neuropsychopharmacol. Biol. Psychiatry 133, 369-376. doi: 10.1016/s0166-4328(02)00025-6

Joshi, H., and Parle, M. (2006a). Nardostachys jatamansi improves learning and memory in mice. J. Med. Food 9, 113-118. doi: 10.1089/jmf.2006. 9.113

Joshi, H., and Parle, M. (2006b). Brahmi rasayana improves learning and memory in mice. Evid. Based Complement. Alternat. Med. 3, 79-85. doi: 10.1093/ecam/nek014

Klencklen, G., Desprès, O., and Dufour, A. (2012). What do we know about aging and spatial cognition? Reviews and perspectives. Ageing Res. Rev. 11, 123-135. doi: 10.1016/j.arr.2011.10.001

Lester, A. W., Moffat, S. D., Wiener, J. M., Barnes, C. A., and Wolbert, T. (2017). The aging navigational system. Neuron 95, 1019-1035. doi: 10.1016/j.neuron. 2017.06.037

Lister, R. G. (1987). The use of a plus-maze to measure anxiety in the mouse. Psychopharmacology 92, 180-185. doi: 10.1007/bf00177912

Martin-Fairey, C. A., and Nuñez, A. A. (2014). Circadian modulation of memory and plasticity gene products in a diurnal species. Brain Res. 1581, 30-39. doi: 10.1016/j.brainres.2014.07.020

McDonald, R. J., Hong, N. S., Ray, C., and Ralph, M. R. (2002). No time of day modulation or time stamp on multiple memory tasks in rats. Learn. Motiv. 33, 230-252. doi: 10.1006/lmot.2001.1111

Nade, V. S., Kawale, L. A., Valte, D., and Shendye, N. V. (2015). Cognitive enhancing effect of angiotensin-converting enzyme inhibitors and angiotensin receptor blockers on learning and memory. Indian J. Pharmacol. 47, 263-269. doi: 10.4103/0253-7613.157114

Parle, M., and Dhingra, D. (2003). Ascorbic Acid: a promising memoryenhancer in mice. J. Pharmacol. Sci. 93, 129-135. doi: 10.1254/jphs. 93.129

Patil, C., Singh, V. P., Satyanarayan, P. S. V., Jain, N. K., Singh, A., and Kulkarni, S. K. (2003). Protective effect of flavonoids against aging- and lipopolysaccharide-induced cognitive impairment in mice. Pharmacology 69, 59-67. doi: 10.1159/000072357 
Pellow, S., Chopin, P., File, S. E., and Briley, M. (1985). Validation of open:closed arm entries in an elevated plus-maze as a measure of anxiety in the rat. J. Neurosci. Methods 14, 149-167. doi: 10.1016/0165-0270(85) 90031-7

Raghavendra, V., and Kulkarni, S. K. (2001). Possible antioxidant mechanism in melatonin reversal of aging and chronic ethanol-induced amnesia in plus-maze and passive avoidance memory tasks. Free Radic. Biol. Med. 30, 595-602. doi: 10.1016/s0891-5849(00)00447-0

Reddy, D. S., and Kulkarni, S. K. (1998). Possible role of nitric oxide in the nootropic and antiamnesic effects of neurosteroids on aging- and dizocilpineinduced learning impairment. Brain Res. 799, 215-229. doi: 10.1016/s00068993(98)00419-3

Sharma, A. C., and Kulkarni, S. K. (1992). Evaluation of learning and memory mechanisms employing elevated plus-maze in rats and mice. Prog. Neuropsychopharmacol. Biol. Psychiatry 16, 117-125. doi: 10.1016/02785846(92)90014-6

Singh, A., Naidu, P. S., and Kulkarni, S. K. (2003). Reversal of aging and chronic ethanol-induced cognitive dysfunction by quercetin a bioflavonoid. Free Radic. Res. 37, 1245-1252. doi: 10.1080/10715760310001616014

Takahashi, Y., Sawa, K., and Okada, T. (2013). The diurnal variation of performance of the novel location recognition task in male rats. Behav. Brain Res. 256, 488-493. doi: 10.1016/j.bbr.2013.08.040
Valentinuzzi, V. S., Kolker, D. E., Hotz Vitaterna, M., Ferrari, E. A. M., Takahashi, J. S., and Turek, F. W. (2001). Effect of circadian phase on context and cued fear conditioning in C57BL/6J mice. Anim. Learn. Behav. 29, 133-142. doi: 10.3758/bf03192822

Vorster, A. P., and Born, J. (2015). Sleep and memory in mammals, birds and invertebrates. Neurosci. Biobehav. Rev. 50, 103-119. doi: 10.1016/j.neubiorev. 2014.09.020

Winocur, G., and Hasher, L. (2004). Age and time-of-day effects on learning and memory in a non-matching-to-sample test. Neurobiol. Aging 25, 1107-1115. doi: 10.1016/j.neurobiolaging.2003.10.005

Conflict of Interest Statement: The authors declare that the research was conducted in the absence of any commercial or financial relationships that could be construed as a potential conflict of interest.

Copyright (C) 2018 Morales-Delgado, Popović, De la Cruz-Sánchez, Caballero Bleda and Popovic. This is an open-access article distributed under the terms of the Creative Commons Attribution License (CC BY). The use, distribution or reproduction in other forums is permitted, provided the original author(s) and the copyright owner(s) are credited and that the original publication in this journal is cited, in accordance with accepted academic practice. No use, distribution or reproduction is permitted which does not comply with these terms. 